\title{
POST-DISCHARGE eLEARNING PLATFORM FOR CARDIAC PATIENTS: DEVELOPING THE FORMAT OF THE EDUCATIONAL UNITS AND RECORDING THE CONTENTS
}

\author{
Borut Kirn PhD ${ }^{1,2}$ \\ ${ }^{1}$ Department of Physiology, Medical Faculty, University of Ljubljana, Ljubljana, Slovenia \\ ${ }^{2}$ Primarius C.I., Ljubljana, 1000, Slovenia
}

\begin{abstract}
Myocardial infarction patients face an increased risk of cardiovascular problems. This risk can be reduced by adjusting one's lifestyle. However, once discharged from the hospital and faced with self-care at home the patient faces a loss of adequate information and diminishing motivation with time after infarction the event. There is a gap of two weeks between being released from the hospital and the patient having any chance of joining organised cardiac rehabilitation programmes, if these are organised by the health system at all. Unfortunately, by that time the highest motivation for lifestyle change has already been lost. An eLearning platform has been put forward to bridge this period, however, the content needs to be carefully prepared to educate and motivate the patient and their family. By analysing how health information is acquired over the Internet today, and by applying social-cognitive learning and storytelling into educational videos we developed a format of an effective educational unit. In order to develop an essential set of educational units seven interviews were recorded with members of medical teams and five with patients who had coronary disease, of which two were with their partners who were their informal caregivers. The format of the educational unit was designed as such that it can be viewed in 4-8 minutes and was composed of three videos featuring peer-patients and medical team members. The videos were accompanied by a short text of up to 50 words, illustrations or quiz questions. From the recorded video material 60 educational videos were edited and used to compose 20 educational units for patients with coronary disease. Legal issues regarding Rights of Publishing and General Data Protection Regulation issues were solved and backend data analytics was developed. Thus, the platform was prepared for next step which will be a large random clinical study.
\end{abstract}

Keywords: eLearning; cardiac rehabilitation; coronary disease; video; telemedicine

Kirn B, et al. JISfTeH 2019; 7:e18(1-7).

DOI: https://doi.org/10.29086/JISfTeH.7.e18

Copyright:@ The Authors 2018

Open access, published under Creative Commons Attribution 4.0 BY International Licence

\section{Introduction}

Cardiovascular diseases are one of the main causes of death worldwide. Incidence and progression for these diseases is highly dependent on lifestyle. Thus, a lifestyle change is a central aim in prevention and rehabilitation. ${ }^{1,2}$ Patients who have had an infarction have increased risk of cardiovascular problems. They belong to a risk group for which a healthier lifestyle adoption is crucial.

The problem is that the motivation to adopt a healthier lifestyle in everyday life decreases with time after the infarction. The patient has the greatest motivation for change immediately after they leave the hospital environment, when they need access to reliable and easy to understand sources of information and support. But this is not adequately exploited.

For example, the patient has an infarction and stays in the hospital for several days. They receive many instructions from the medical team and insight as to what this disease means for their life. However, when discharged from the hospital, they return home to realise that they have forgotten most of the instructions which were given in the first place (up to $85 \%$ ), and the optimal time for change has been lost. ${ }^{3}$

An eLearning platform for educational and motivational support has been suggested to bridge the gap. There are many existing Internet information platforms like heartfailurematters.com and healthtalkonline.org. They have reliable and certified information about the infarction and/or cardiac failure. All these pages are standard passive Internet pages with information organised through a menu structure. The problem with these kinds of pages is that even for an educated person in the field the sheer amount of information causes confusion and loss of motivation. The average user is even more frustrated and lost with all the available information. The entry barrier for information acquisition is set too high for the average user. In addition, it is very 
difficult to obtain feedback information about individual user's knowledge level and/or individual patterns of learning and self-motivation. The educational Internet platform should be made easier to understand and more interesting. The entry barrier should be lower and adherence to the Internet education service should be increased. To achieve this, new knowledge in human-to-Internet interaction in addition to known human behaviour in interaction with mass media approaches, should be applied.

It is known that the average duration of high attention towards any content on the Internet is typically from 3 to 6 minutes. Video information is favoured compared to textual. Video is more compelling, fun and conveys information better. A personal address from the physician further increases trustfulness. Very well accepted among patients are also the experiences of other patients. Behavioural characteristics are conveyed better by copying personal habits of others compared to listening to an academic explanation. Integrated quizzes increase the perception of seriousness. Gamification increases fun. Praises increase satisfaction and adherence to the information source. In addition, the Internet enables automated analysis of an individual user's learning characteristics.

The Internet service is meant to complement organised cardiac rehabilitation programmes. Both should start as soon as possible after the patient is discharged from the hospital. For example, this kind of service is very relevant in Slovenia because it typically takes between 2 to 12 weeks before patients have a chance to join an organised cardiac rehabilitation programme and with it gain access to a trustful source of information. The aim of this study is to define the principles upon which the content should be built, to define the format of one educational unit and to develop 20 individual units for eLearning contents for patients with acute myocardial infarction.

\section{Methods}

The critical steps in the process of using an eLearning platform are firstly informing the patient about the availability of such a platform and of its importance for the patient, secondly to achieve easy log in into the platform and finally, to use the contents. For the first step a selfexplanatory voucher with the login codes needs to be developed. The process of discharge is usually very information demanding for patients and for the medical team. Thus, the only additional intervention from the medical team is to hand over a voucher which must be graphically compelling and easy to understand. The second step is the individual $\log$ in which needs to be particularly straight forward and easy to complete in order to reduce drop out of users at this step. The third step is to ensure continuous use of the contents. To maximise this last step, we followed the concepts previously developed in education of the elderly and education over Internet which are elaborated in the following paragraphs.

\section{Social-cognitive learning theory}

It has been shown that patients highly value peer information. $^{4}$ It is easier for patients to adopt another patient's life-style habits than to analytically understand why these habits are good for them. As it has been shown with Social-cognitive learning theory a complex behaviour can be learned by watching others. ${ }^{5}$

Storytelling as a powerful way of transmitting information The narrative way of conveying information is much more powerful than just enumerating facts or transmitting plain information. Personal stories and gossip make up $65 \%$ of our conversations. A story should be simple since it appears to be more interesting than a complicated one. As reported by Hasson et al. ${ }^{6}$ a story is the only way to activate parts in the brain so that a listener turns said story into their own idea and experience. $^{7}$

For example, women who watched a narrative video compared to an informational video about breast cancer survival experienced a more positive and more negative affect respectively. They identified more with the source of the message and were more engaged with the video., Women who watched the narrative video also reported fewer barriers to mammography, more confidence that mammograms work, and were more likely to perceive cancer as an important problem. These women were also less likely to feel upset. ${ }^{10}$ The benefits of storytelling have been shown also by neuro-cinematics, where quantitative neuroscience is used while watching different film styles. ${ }^{11}$

\section{Duration and composition of video}

The average length of the most watchable videos on YouTube is between $1 \mathrm{~min} 45 \mathrm{~s}$ and $4 \mathrm{~min} 11 \mathrm{~s} .{ }^{12} \mathrm{Wistia} . c o m$, an Internet video providing company, reports that the most engaging length of an online video is up to $30 \mathrm{~s}$. The average 30 s video was viewed $85 \%$ of the way through, while the average 2 minute video was viewed on average $50 \%$ of the way through. The average viewing percentage stays consistent for 2 minute videos to 10 -minute videos. ${ }^{13,14}$

In general, educational videos are longer than entertainment videos, but also less engaging. The videos should be front-loaded with the most important, new and specific parts of the doctors and patients' messages.

\section{Power of visual communication}

Communication which incorporates visual components is far more effective. People only remember $10 \%$ of what they hear, $20 \%$ of what they read and $80 \%$ of what they see and do. ${ }^{15,16}$ By using graphics in the units, we expedite and increase the level of communication. ${ }^{17}$

\section{Speaker-listener relationship as a form of successful communication}

The speaker's activity is spatially and temporally coupled with the listener's activity; the greater the anticipatory speaker-listener coupling the greater the understanding. ${ }^{18}$ 


\section{Health communication}

Health communication has proven techniques which influence individual and community decisions that enhance health. ${ }^{19,20}$ There are different strategies which can be incorporated:

\section{Entertainment-education}

Several research studies have demonstrated that even brief exposure to health information and behaviours through entertainment media can have strong effects. ${ }^{21,22}$

Interactive Health Communication

Interactive technology has created new opportunities for health communication that can overcome barriers such as low literacy and expand opportunities to tailor and personalise information. One of such applications is Comprehensive Health Enhancement Support System (CHESS), for which there is impressive research evidence of its potential for reducing disparities. ${ }^{22,23}$

Interpersonal communication

Interpersonal communication theory helps us understand the provider-client interaction, the role of social support in health, and the ways in which interpersonal relationships influence health behaviours and decision-making. Clearly, the relationship between patient and provider can exacerbate health disparities. Poor communication is linked to health disparities. $^{22,24,25}$

\section{Increased attention with gamification of the problem}

Gamification is the use of game thinking and game mechanics in a non-game context to engage users and solve problems. ${ }^{26}$ It is used also to improve user engagement and learning. Gamification techniques strive to leverage people's natural desires for competition, achievement, status, selfexpression, altruism, and closure. A core gamification strategy is to reward players who accomplish a desired task. Patients with different diagnosis can already benefit and improve their health by some gamification's techniques. However, lots of space remains for implementing gamification into health education and behaviour. ${ }^{27,28}$

\section{Development of educational unit}

The frame of an educational unit was developed taking all considered concepts into account. All units are to be structured in the same way, ensuring that no additional efforts are needed from the patient to understand the structure of the information delivered to them. Thus, the unit:

- was designed to be normally viewed within 4-8 minutes

- includes two or three videos each from 30s - 120s long

- one video always features medical team member and one features a peer-patient

- short texts (up to 50 words), an illustration or a quiz complement the contents of the videos.

\section{Results}

Originally the eLearning platform for cardiac patients was developed for patients in Slovenia. However, the largest and most elaborate platform content was developed for
Hartcentrum Hasselt, Belgium. Even though the core topics of interest are similar for all patients from different countries each country has a specific culture of communication. To achieve strongest identification and content uptake the contents needs to be culture specific. Thus, a complete set of content was developed for the Flemish region, Belgium.

The three steps on which the success of the platform depends are, the relay of initial information in the clinic, ease of log in onto the Internet page, and encouraged continuous usage. These steps are successive and only the successful accomplishment of a previous step enables the execution of the next one. Therefore, the first contact with the patient in the clinic is essential and to complete it successfully a graphical voucher with anonymous codes was developed. Many design cycles were performed to optimise the voucher and to optimise its delivery attitude in the clinic. Thus, upon discharge the patients received a self-explanatory voucher from the hands of the discharge nurse with minimal explanation. The voucher provides access codes with which the patient enters the eLearning platform through the login page. (Figure 1)

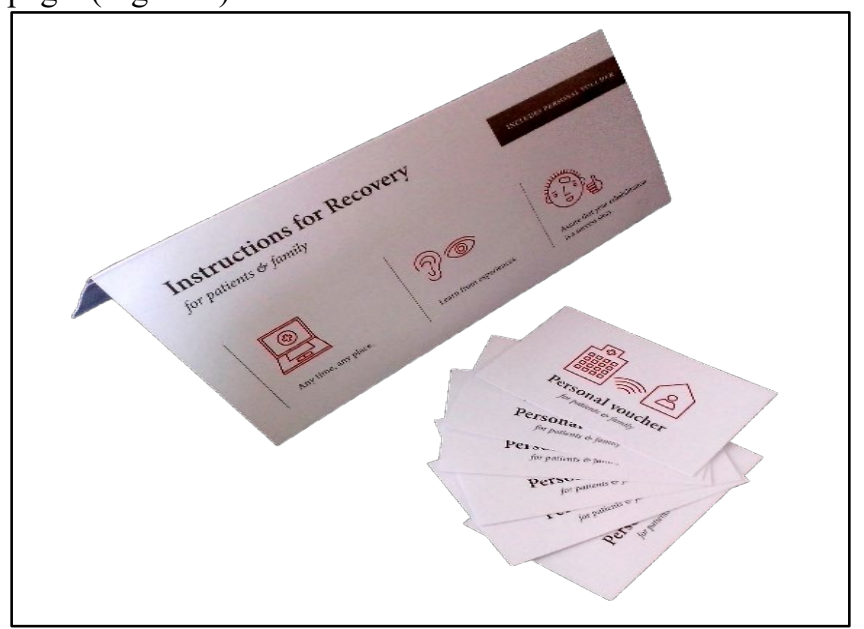

Figure 1. The vouchers with anonymous personalised entry codes (left) and the login page (right).

When preparing the contents, interviews with seven members of a medical team were recorded (three doctors, a dietitian, a psychologist, a rehabilitation therapist and nurse) as well as interviews with five peer-patients, of which two were accompanied by their partners who were their informal caregivers. From the recorded interviews 60 videos were edited and distributed into 20 different units, each unit containing three videos. The videos were subtitled to ease understanding of spoken words and/or enable watching them with sound turned off. For each unit, up to three texts of up to 50 words each were developed such that they complemented the videos to form a comprehensive and easy to understand informational unit. (Figure 2)

Altogether 20 units were developed and made available to the patients. The topics were determined according to suggestions from doctors in Slovenia and Belgium and from 


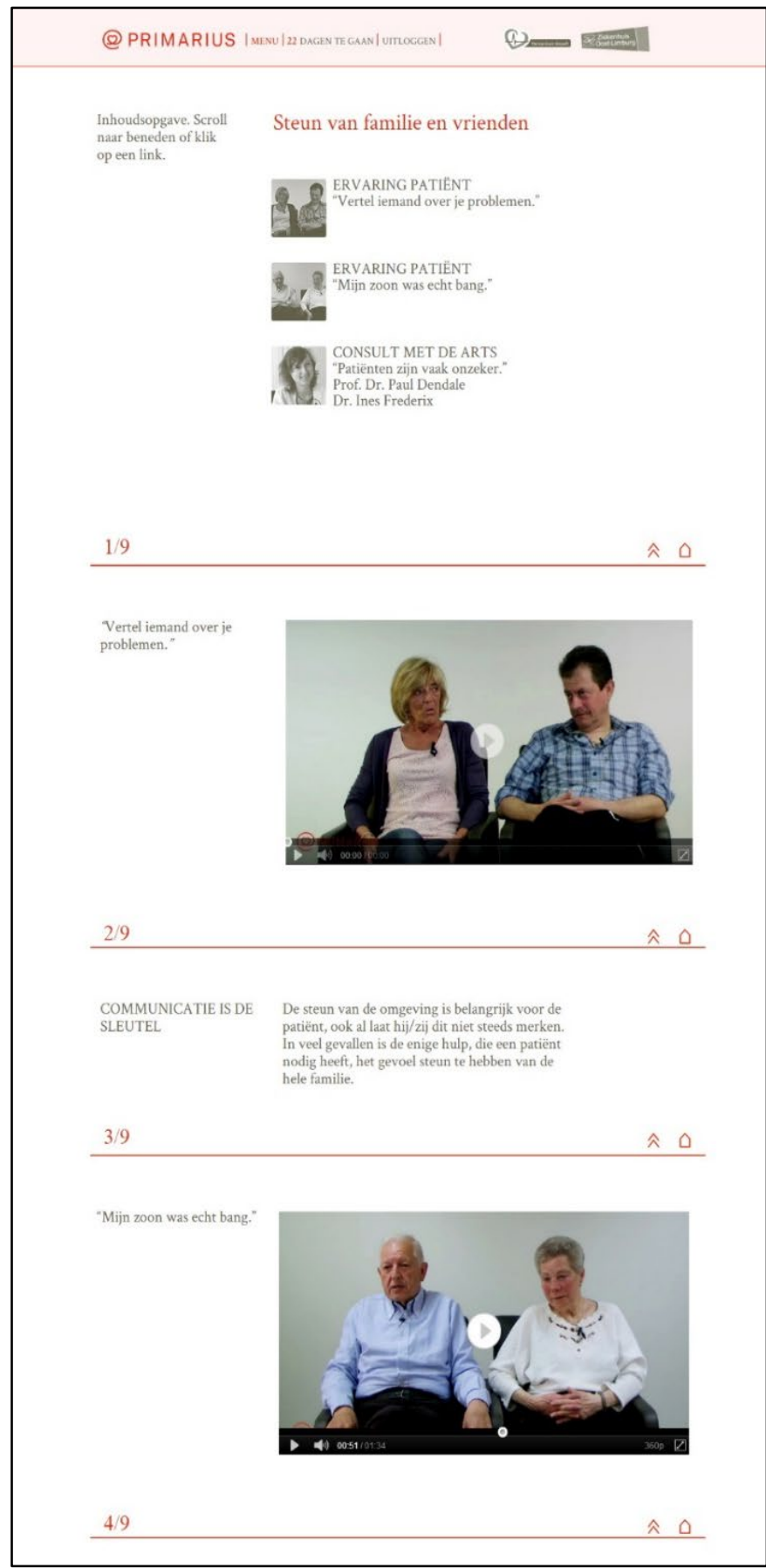

Fig 2a. peer-patients and one featuring the doctor. Between the videos are three blocks of text.

four sessions with focus groups of 10 patients with coronary disease from the Coronary Club Ljubljana, Slovenia. The final cut was limited with available video material. All topics listed in the main menu which opens after a successful login are shown in Figure 3. Each menu tile is designed with a photo of a medical team member or peer-patient.
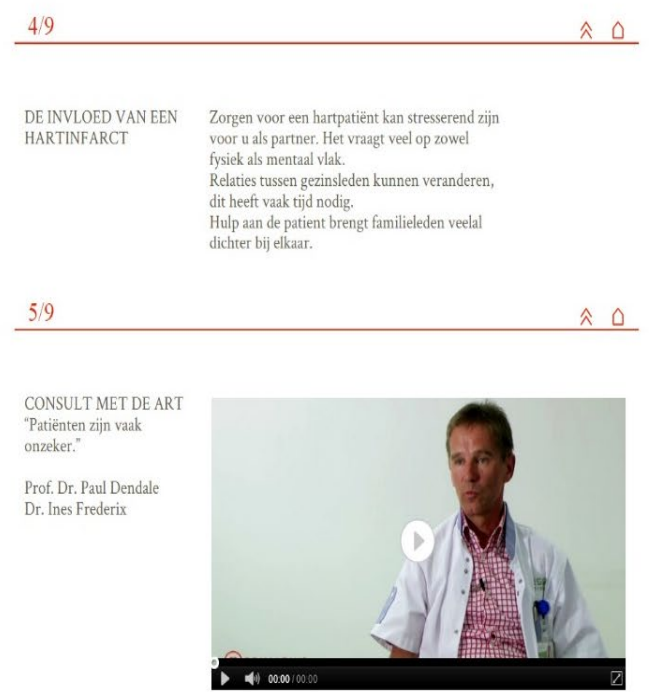

$6 / 9$

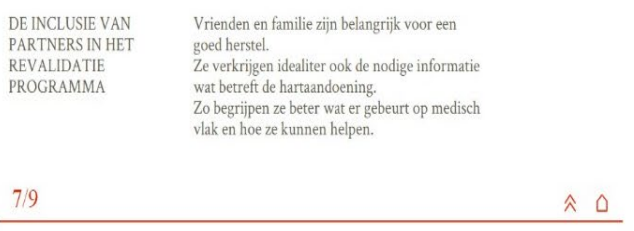

QUIZ

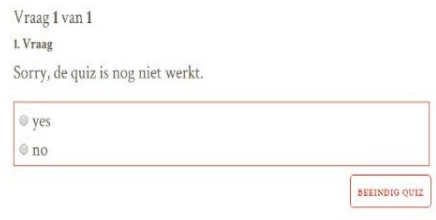

$8 / 9$ $\hat{\wedge}$

Inhoud geautoriseerd door Hartcentrum Hasselt, Jessa Clinic Q Gecreërd PRIMARIUS info@primarius.be

$9 / 9$ 스

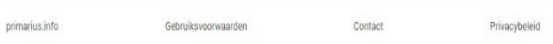

Fig 2b.

\section{Discussion}

The experiences with recording the videos were very positive. During the interviews it was very important that the interviewer was focused on the answers and The patients were very open in discussing their experiences. Each inter- 


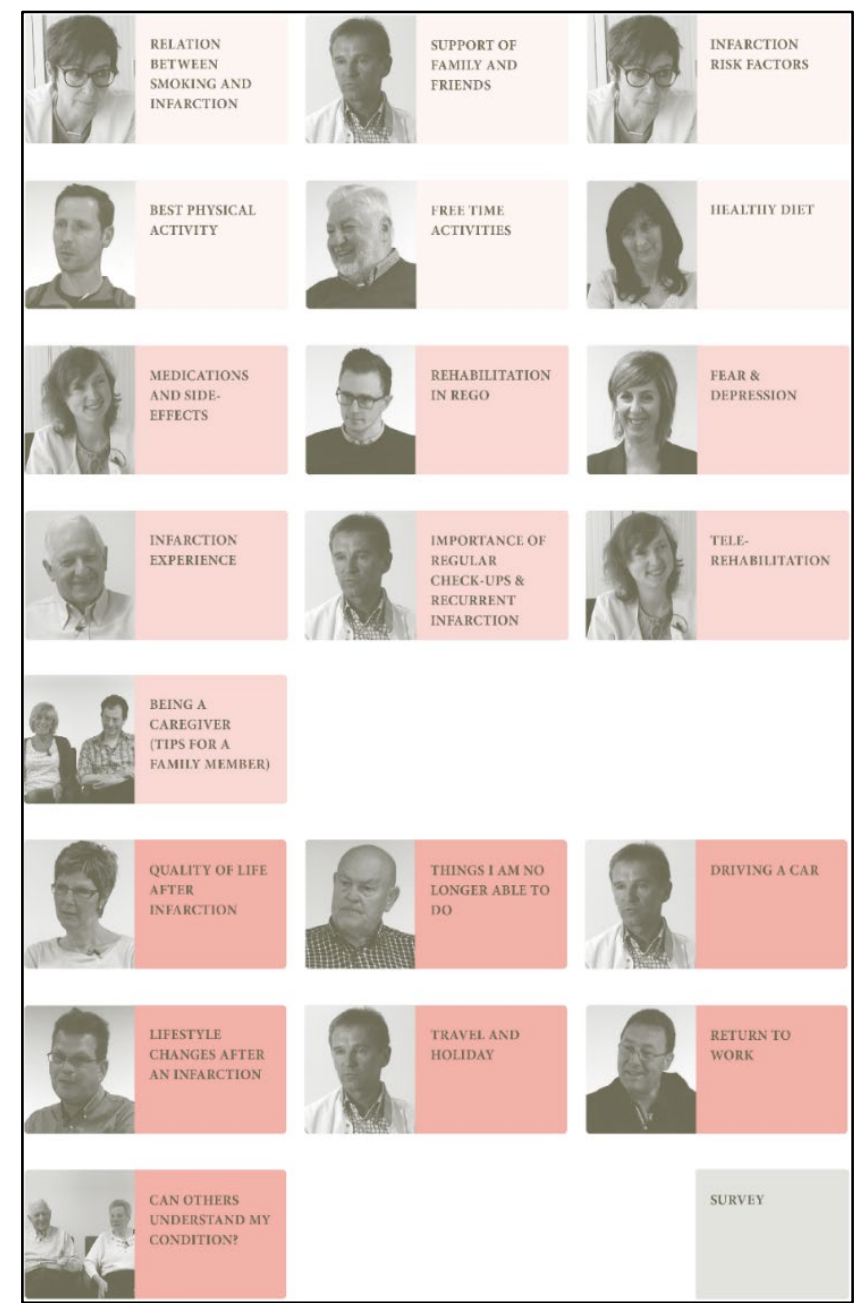

Figure 3. eLearning platform main menu with titles of all 20 topics and a survey title.

view discussed questions relating to all 20 topics and just after all the material was collected the best answer for the given topic was selected and edited for final use in the educational units.

The legal issues were solved regarding content authorships and right for publishing by signing a contract. The GDPR (General Data Protection Regulation) information regarding recording of platform usage was developed and explained to patients.

The creation of the contents was a laborious process. Selection of the correct and best answers while including each and all of the participants was a complex process. It was necessary for the video editor to become well informed regarding the content and be able to collaborate with the medical team. Video postproduction presented the largest proportion of work carried out. It is financially unsustainable for each clinic to prepare the videos for their patients on their own. Therefore, the content prepared should be aimed for distribution within one state or language group. The distribution platform is thus developing towards a decentralised platform with multiple content creator teams, evaluators and distributors.

A clinical trial on the first use of the platform will study the percentage of patients that receive the voucher and subsequently also successfully log in, how long they stay on the platform, which topics they watch, and how many times they $\log$ in. The clinical study should reveal clinically relevant influence of platform use on the treatment outcome such as improvement in knowledge, adherence to behavioural changes as well as its influence on readmissions, medical complications and patient satisfaction.

\section{Corresponding author: \\ Borut Kirn PhD \\ Department of Physiology \\ Medical Faculty \\ University of Ljubljana \\ Zaloška 4, 1000 Ljubljana \\ Slovenia \\ Tel.: +38640624021 \\ Fax: +38615437501 \\ E-mail:borut.kirn@mf.uni-lj.si}

Conflict of interest. The author is a principal developer of the platform which is a commercially available product.

Acknowledgements. The author would like to thank the members and the staff of Coronary Club Ljubljana, Slovenia for their initial open discussions and focus groups for defining the needs of the patients. Furthermore, I would like to acknowledge the work and help of Dr. Paul Dendal and Dr. Ines Frederix who enabled and participated in the content's development for Hartcentrum Hasselt, Belgium.

Funding. The platform structure and IT development were financed from the author's private funding and developers' team personal time investments. The participation of the Hartcentrum Hasselt team in the content development was financed by a research grant which is aimed to provide results for future clinical study on the influence of the platform on treatment outcome of the patients.

\section{References}

1. Huy C, Thiel A, Diehm C, Schneider S. AdhärenzDefizite auf allen Ebenen. Dtsch Med Wochenschr 2010;135(43):2119-2124. DOI: 10.1055/s-00301267489

2. Hüppe A, Raspe H. Zur Wirksamkeit von stationärer medizinischer Rehabilitation in Deutschland bei chronischen Rückenschmerzen. Rehabilitation 2005;44(01):24-33. DOI: 10.1055/s-2004-834602

3. Kessels RP. Patients' memory for medical information. $J$ R Soc Med 2003;96(5):219-222. DOI:

$10.1258 / \mathrm{jrsm} .96 .5 .219$ 
4. Sillence E, Briggs P, Herxheimer A. Personal experiences matter: what patients think about hypertension information online.He@lth Inform Internet 2004;42(1): 3-5. DOI:

10.1145/1125451.1125698

5. Bandura A. (1976): Lernen am Modell. Ansätze zu einer sozial-kognitiven Lerntheorie. Stuttgart: Ernst Klett.

6. Hasson U, Ghazanfar AA, Galantucci B, Garrod S, Keysers C. Brain-to-brain coupling: a mechanism for creating and sharing a social world. Trends $\operatorname{Cogn} \mathrm{Sci}$ 2012;16(2):114-121. DOI: 10.1016/j.tics.2011.12.007

7. Lerner Y, Honey CJ, Silbert LJ, Hasson U. Topographic mapping of a hierarchy of temporal receptive windows using a narrated story. $J$ Neurosci 2011;31(8):2906-2915. DOI:

10.1523/JNEUROSCI.3684-10.2011.

8. McQueen A, Kreuter MW, Kalesan B, Alcaraz KI. Understanding narrative effects: the impact of breast cancer survivor stories on message processing, attitudes, and beliefs among African American women. Health Psychol 2011;30(6):674-682. DOI: 10.1037/a0025395

9. McQueen A, Kreuter MW. Women's cognitive and affective reactions to breast cancer survivor stories: a structural equation analysis. Patient Educ Couns 2010;81 Suppl:S15-21. DOI: 10.1016/j.pec.2010.08.015

10. Bollinger S, Kreuter MW. Real-time moment-tomoment emotional responses to narrative and informational breast cancer videos in African American women. Health Educ Res 2012;27(3):537543. DOI: $10.1093 /$ her/cys047

11. Hasson U, Landesman O, Knappmeyer B, etal. Neurocinematics: The neuroscience of films.

Projections: 2008;2:1-26.

https://nyuscholars.nyu.edu/en/publications/neurocine matics-the-neuroscience-of-films

12. Savage J. How long should a corporate video be? (With 4 Studies)

(2015) Available at: https://boldcontentvideo.com/2015/11/19/how-longshould-a-corporate-video-be-with-4-studies/ accessed 12 June 2019.

13. Savage C. Does length matter? It does for video! (2009). Available at: http://wistia.com/blog/doeslength-matter-it-does-for-video/ accessed 1 June 2019.

14. Savage C. 4 Ways to keep viewers engaged in an online video. (2011). Available at: http://wistia.com/blog/4-ways-to-keep-viewersengaged-in-an-online-video/ accessed 1 June 2019.

15. University of Leicester. Student learning development. (2017) Available at:

https://www2.le.ac.uk/offices/ld/resources/presentation s/visual-aids accessed 12 June 2019.
16. Furman O, Dorfman N, Hasson U, Davachi L, Dudai Y. (2007) They saw a movie: long-term memory for an extended audiovisual narrative. Learn Mem 2007;14(6):457-467. DOI: 10.1101/lm.550407

17. Levin JR. (1989). A Transfer of Appropriate Processing Perspective of Pictures in Prose, Knowledge Acquisition from Text and Prose. Elsevier Science Publishers, BV North Holland. DOI: https://doi.org/10.1016/S0166-4115(08)62149-4

18. Stephens GJ, Silbert LJ, Hasson U. Speaker-listener neural coupling underlies successful communication. Proc Natl Acad Sci 2010;107(32):14425-14430. DOI: https://doi.org/10.1073/pnas.1008662107

19. De Negri B, Brown DL, Hernández O, Rosenbaum J, Roter D. Improving Interpersonal Communication Between Health Care Providers and Clients. Quality Assurance Methodology Refinement Series. Bethesda US. 1997:3-59.

https://www.usaidassist.org/resources/improvinginterpersonal-communication-between-health-careproviders-and-clients

20. Roter D, Katz N. Correlates of provider behavior: a meta-analysis. Medical Care 1988;26:657-675. PMID: 3292851

21. Beck V, Huang GC, Pollard WE, Johnson TJ. TV Drama viewers and health information. Paper presented at the American Public Health Association 131st Annual Meeting and Exposition, San Francisco, California 2003.

22. Freimuth VS, Quinn SC. The contributions of health communication to eliminating health disparities. $\mathrm{Am} \mathrm{J}$ Public Health 2004;94(12):2053-2055. DOI: 10.2105/AJPH.94.12.2053

23. Street RL Jr, Rimal RN. Health promotion and interactive technology: A conceptual foundation. Health promotion and interactive technology: theoretical applications and future directions. Mahwah, NJ: Lawrence Erlbaum Associates. 1997:1-18. https://psycnet.apa.org/record/1997-08592-001

24. Ashton CM, Haidet P, Paterniti DA, et al. Racial and ethnic disparities in the use of health services: bias, preferences, or poor communication? J Gen Intern Med 2003;18(2):146-152. DOI: $10.1046 /$ j.15251497.2003.20532.x

25. Beaulieu M, Haggerty JL, Beaulieu C, et al. Interpersonal communication from the patient perspective: comparison of primary healthcare evaluation instruments. Healthc Policy 2011;7(Spec Issue): 108-123. PMID: 23205039

26. Huotari K. and Hamari J. Defining Gamification - A Service Marketing Perspective. Proceedings of the 16th International Academic MindTrek Conference 2012, Tampere, Finland, October 3-5. DOI: $10.1145 / 2393132.2393137$ 
27. Deterding S, Dixon D, Khaled R. and Nacke L. From game design elements to gamefulness: Defining "gamification". Proceedings of the 15 th International Academic MindTrek Conference 2011;9-15. DOI: 10.1145/2181037.2181040

28. McCallum S. Gamification and serious games for personalized health. Stud Health Technol Inform 2012;177:85-96. DOI: 10.3233/978-1-61499-069-7-85 